\title{
Uma Nova Anatomia é Destino?
}

ORTEGA, Francisco J. G.

O corpo incerto.

Corporeidade, tecnologias médicas e cultura contemporânea.

Rio de Janeiro: Garamond, 2008. 256p.

\section{| 'ilian Krakowski Chazan |}

${ }^{1}$ Médica, psicanalista, doutora em Saúde Coletiva e pós-doutoranda do IMS-UERJ. Endereço eletrônico: liliankc2004@yahoo.com.br.

À primeira vista, o título do livro $O$ corpo incerto faz-nos crer que se trata de um livro sobre o corpo. Ele é bem mais do que isso. Francisco Ortega nos leva em uma viagem por diversas questôes contemporâneas, utilizando o corpo e as tecnologias médicas que o escrutinam como ponto de partida, em um livro denso, bom para pensar e levantar indagações. Sua proposta é escanear um objeto fundamental e fundante na cultura contemporânea: a questão do corpo, mediante uma reflexão por diversos ângulos, correspondendo aos diversos capítulos.

Construído em quatro partes, bastante distintas entre si, sua estrutura é análoga às diversas tecnologias de imagem discutidas no terceiro capítulo. Os capítulos funcionariam como os cortes das tecnologias de imagem médica, apresentando facetas diferentes de uma mesma questão, apresentadas mediante diversas tecnologias do saber, basicamente filosofia e história; a composição final fica por conta do leitor. A bibliografia é extensa, atualizada e diversificada, consistindo em uma fonte rica de pesquisa para todos que se interessam não apenas pelas questôes referentes ao corpo mas pelas discussōes críticas acerca da contemporaneidade. Ao longo do livro, o corpo é, portanto, um leitmotiv que articula as diversas discussóes. Grosso modo, poderíamos dizer que o capítulo 1 trabalha a construção de uniformidade; no segundo, trata da busca de singularidade dentro do paradigma de centralidade do corpo; no terceiro, discute como se constitui o corpo contemporâneo, mediado por tecnologias de imagem médica; finalmente, no quarto aborda o debate sobre o estatuto do corpo na contemporaneidade. A rigor, os capítulos podem ser lidos separadamente, pois as abordagens são distintas. O primeiro e o último, especialmente, têm um caráter ensaístico bastante acentuado. Pela densidade e riqueza de material apresentadas por Francisco Ortega em $O$ 
corpo incerto, que o tornam consulta obrigatória para os pesquisadores das mais diversas áreas, seria extremamente útil a existência de um índice remissivo.

No primeiro capítulo, o autor nos oferece uma genealogia da ascese, em uma reflexão brilhante e vigorosamente crítica da cultura do corpo contemporânea. Contrasta as asceses da Antiguidade, práticas de liberdade e com um sentido político e social, com a bioascese contemporânea, disciplinar e de cunho eminentemente individualista, mostrando de modo claro como práticas semelhantes com objetivos divergentes produzem processos de subjetivação opostos. Diferentes momentos históricos produziram distintas formas de ascetismo e processos de subjetivação. As asceses da Antiguidade visavam à libertação do sujeito de seu próprio corpo; a bioascese promove e reforça a ancoragem do sujeito em seu próprio corpo, como ponto de partida e, ao mesmo tempo, objetivo último. Enquanto na ascese da Antiguidade o sujeito buscava a singularização e a demarcação nítida de uma identidade, Ortega mostra-nos que na bioascese o objetivo principal é a conformidade à norma, uniforme e, sobretudo, ditada pela cultura contemporânea que coloca a saúde e perfeição do corpo como parâmetros a serem [per]seguidos incessantemente.

Geram-se alguns paradoxos curiosos, pois uma prática de cunho eminentemente individualista produz subjetivaçôes disciplinadas e equalizadas, justo o oposto da identidade construída por meio da singularização. Em uma cultura de visibilidade, busca-se a invisibilidade pela conformidade à norma. No pensamento antigo, grecolatino, a ascese corporal sempre estava acompanhada de uma dimensão espiritual. A dietética, para os gregos, continha um significado estético e político, visando ao outro e à sociedade, e tratava-se, como aponta Ortega, de uma prática social: "Ocupar-se consigo mesmo é ocupar-se dos outros, colocando a justiça no centro mesmo do cuidado" (p. 25). A partir da comparação entre a ascese antiga e a bioascese contemporânea, o autor aborda as novas formas de sociabilidade - ou biossociabilidade -, valores e crenças que são erigidos nos dias atuais calcados na medicalização ampla da sociedade. Aponta os diversos paradoxos produzidos por esta situação, como a busca frenética pela autonomia, que torna a todos dependentes das tecnologias em geral, e das tecnologias do poder em particular - as mesmas que constroem a autonomia como um valor moral, diga-se de passagem.

Sem cair em maniqueísmos simplistas, Ortega nos mostra como tal situação é engendrada, e a ambivalência gerada pelo culto ao corpo que produz, como as 
duas faces da mesma moeda, simultaneamente o cuidado de si e busca do prazer a todo custo.

A mesma cultura que produz a obsessão pela malhação, a dieta saudável, e qualquer produto novo de fitness, saúde ou beleza, gerou também os casos extremos de sedentarismo, a fast-food, e toda uma gama de drogas sintéticas (p. 38).

Outros desdobramentos são apontados, tais como o esfumaçamento entre trabalho e lazer, e a potencialização mútua entre bioascetismo e displicência somática. A contemporaneidade transformou o corpo em objeto de consumo, com o body building, e acentua-se a disciplina com o adestramento corporal, nos termos de Foucault. Conforme aponta Ortega, nos dias atuais "o corpo torna-se o lugar da moral, é seu fundamento último e matriz da identidade pessoal” (p. 40). O selfé corporificado, por meio da fitness. As práticas bioascéticas fundem corpo e mente e ultrapassam dicotomias, como, por exemplo, interioridade e exterioridade: o sujeito é o seu corpo, seu self exteriorizado; a aparência - boa ou má, pelos padrões vigentes - reflete a moral do indivíduo. Modificam-se a possibilidade de intimidade, privacidade, as conseqüências das "deficiências morais", como a falta de disciplina corporal, tornam-se - literalmente - visíveis. Não há como proteger-se do olhar crítico do outro a não ser escondendo-se na norma, adaptando-se ao padrão em vigor. A ascese clássica, que continha um aspecto político e/ou religioso, substituída pela bioascese perde essa dimensão. Ou, como sintetiza ironicamente o autor: "A hipertrofia muscular se traduz em atrofia social” (p. 48). Ao invés de se mudar o mundo, muda-se o corpo mediante variadas tecnologias.

Ortega finaliza o capítulo ressaltando que apesar do tom crítico em relação à cultura somática, à bioascese e às bioidentidades, elas constituem nosso cotidiano, e em alguns aspectos apresentam avanços em relação à saúde e à construção de identidades como, por exemplo, para os portadores de deficiências. Reitera que a postura crítica é essencial para que se consiga lidar com esses elementos constituintes da contemporaneidade, de modo que as inovaçôes que se multiplicam nos dias atuais se tornem práticas de liberdade e não de sujeição.

No segundo capítulo, o autor analisa algumas práticas de modificações corporais, concentrando-se na tatuagem, branding, piercing e implantes. Seu argumento é o de que essas modificações representam, em termos fenomenológicos, esforços para fugir à norma e recuperar a dimensão do vivido corporal. Pensando por uma 
perspectiva antropológica - a nosso ver inescapável em uma discussão acerca do corpo -, algumas perguntas que se poderia levantar seriam: em que estas práticas seriam diferentes das escarificações rituais? E até que ponto, ao se tentar escapar da norma, não se criam apenas outras normas e pertencimento a grupos? Por outro lado, será que estas supostas rupturas com a norma não serviriam também - pelo contraste - para reiterar a norma vigente? Ainda dentro desta perspectiva, outro ponto a pensar consiste no uso do termo "cultura", pelo autor, que nitidamente aborda em sua discussão práticas, valores e crenças circulantes em grupos urbanos de um modo um tanto generalizante.

Contrapondo-se a autores que consideram essas práticas como "estilos", ou outros, que as consideram patologias merecendo medicalização, nosso autor propõe uma abordagem que leve em conta a agência dos atores envolvidos, uma perspectiva compatível com seu argumento acerca da centralidade do corpo na contemporaneidade. Aponta que os critérios tradicionais de agrupamento foram deslocados para o corpo e, portanto, doenças, saúde, performances corporais, entre outros, passaram a se constituir como referenciais organizadores da vida social e subjetiva. Modificações corporais trazem a ilusão de uma estabilidade, pela construção de um universo em miniatura no próprio corpo e, ao mesmo tempo, servem como afirmação definitiva de pertencimentos ou de identidades que, em princípio, prescindiriam do olhar do outro para se constituir. As modificações corporais se contrapóem à cultura da fitness, tentando resgatar o vivido corporal, assim como os ditos comportamentos de risco buscariam libertar o corpo da monotonia sensorial por meio da dor, do medo e da morte. Para o autor, a contemporaneidade é marcada por uma anestesia sensorial auxiliada pela preponderância da visualidade sobre os outros sentidos como forma de produção de verdades. A visão seria o menos corpóreo dos sentidos, e a invenção de tecnologias de imagem médica, a partir de fins do século XIX, aprofunda essa noção, em detrimento do tato e da audição como modos de apreender e compreender o corpo. Para Ortega, as modificações corporais estariam na contracorrente desse processo, como uma recusa ao império da visão.

O terceiro capítulo constitui o núcleo denso e extenso do livro, trazendo a história cultural da visualização médica do corpo. $\mathrm{O}$ autor disseca, por meio dessa história, a constituição do lugar da visão para a produção de um novo corpo, escrutinado e ressignificado. Sem perder de vista uma transformação cultural e 
social mais geral, aprofunda-se nessa história para se indagar sobre as conseqüências, de ordens variadas, dessa busca incessante de visualização do invisível. A hipótese sustentada por Ortega é que esta ânsia se vincula ao fato de que, no cotidiano, o interior do corpo escapa à apreensão subjetiva e fenomenológica - exceto nos casos da dor e do prazer. As tecnologias de imagem médica carregam culturalmente a sedução de, supostamente, produzirem informaçóes objetivas que transformariam o corpo incerto em um corpo sem ambigüidades. $\mathrm{O}$ autor reafirma sua abordagem calcada em um paradigma de corporeidade associada à experiência subjetiva, contrapondo-se ao construtivismo radical. Para ele, a fenomenologia da corporeidade constitui-se como uma ferramenta mais útil para a análise e questionamento das conseqüências de uma corporeidade produzida e/ou mediada pelas tecnologias de imagem médica. Sustenta que o sucesso das tecnologias de imagem médica resulta do fato de lidarem - ou proporem - uma alternativa para o que ele aponta como ambivalência ontológica fundamental e constitutiva do visceral: nosso interior anatômico nos é estranho; as tecnologias apresentariam - ao menos teoricamente a possibilidade de torná-lo familiar e controlável. Ainda assim, o suposto conhecimento objetivo proporcionado por elas consiste em uma apreensão indireta do interior do corpo, em parte pelo motivo óbvio da mediação tecnológica mas, sobretudo, porque para as imagens técnicas adquirirem algum significado é imprescindível o olhar de um observador treinado e socializado em determinados códigos visuais - necessariamente subjetivos - para interpretá-las. ${ }^{1}$

A partir do século XVI, conhecimento do interior do corpo e conhecimento de si se tornaram coincidentes e presentes na cultura. $\mathrm{O}$ homem anatomizado é o mesmo que se busca conhecer. Ortega expõe a história das dissecações, desde os pré-helênicos até o momento da constituição da anatomia patológica, passando pela ruptura epistemológica representada pela atuação de Vesálio e a geração do paradigma anatômico. Este é também o momento fundante para o estabelecimento e consolidação da visualidade como elemento central para o conhecimento do corpo e a instituição de uma norma. O autor discorda radicalmente, nesse ponto, da proposição de Foucault em $O$ nascimento da clínica, quando este coloca Bichat como responsável por uma ruptura epistemológica no conhecimento do corpo e da doença. Para Ortega, esta ruptura teria ocorrido com Vesálio e com o surgimento da anatomia moderna ou, nos termos de Sawday (1996), com a cultura da dissecação. A tradição anatômica que objetiva corpos dissocia o homem do cosmos e é fundante para o dualismo 
corpo-mente, assim como para a desvalorização da magia do corpo e um relativo desinvestimento simbólico. Por outro lado, é erigido um simbolismo moral, político e religioso concernente ao controle sobre a morte, por meio do conhecimento sobre o corpo. A partir desse ponto, o cadáver passa a ser visto na terceira pessoa, possibilitando o surgimento de objetivismo e reducionismo acerca do corpo. $\mathrm{O}$ pensamento médico toma o cadáver anatomizado como modelo, um elemento que se encontra na base das tecnologias médicas, especialmente as de imagem que passam a poder penetrar nos corpos sem que estejam mortos. ${ }^{2}$

Prosseguindo em sua discussão com Foucault, sustenta a existência de uma continuidade na metáfora anatômica surgida no Renascimento, até os dias atuais, passando pela fisiognomia e a frenologia do século XIX. Nos estudos de fisiognomia, o corpo é apresentado de um modo fragmentado que, segundo Ortega, guardaria uma semelhança com a fragmentação oferecida pelas tecnologias de imagem médica. Este argumento, do meu ponto de vista, é um dos poucos pontos discutíveis do livro, pois deixa de lado uma questão relevante: na medida em que os objetivos de tais estratégias propõem tipos diferentes de conhecimento e partem de paradigmas diferentes sobre o sujeito - o primeiro sendo uma busca de conhecimento sobre a subjetividade ou o caráter, calcado em um paradigma indiciário, e as segundas buscando patologias escondidas na profundidade do corpo, calcadas em um paradigma anatomopatológico -, a semelhança entre as fragmentações teria um caráter apenas formal. Pode-se falar, a meu ver, de algumas continuidades e algumas rupturas, escapando-se de generalizações.

Ainda nesse capítulo, Ortega passa a discutir a construção da objetividade, revisando um artigo já clássico de Daston e Galison (1992), no qual os autores demonstram a historicidade do conceito, assim como de que maneira esta qualidade foi investida de um caráter moral, produtor de verdades, que deriva diretamente na valorização da objetividade mecânica, que encontraria no surgimento da fotografia seu epítome. Rapidamente essas imagens foram utilizadas na medicina. A moral da objetividade mecânica, "neutra", "científica", é correlata à moral vitoriana de autodisciplina e contenção. O cientista é também um asceta. Ainda assim, as imagens fotográficas "neutras", "científicas" e "objetivas" necessitam ser lidas e, portanto, interpretadas, um processo subjetivo obrigatoriamente informado e modelado pelos códigos visuais vigentes. Novas tecnologias de imagem, a partir do surgimento dos raios X, colocam esta tensão em evidência. A multiplicação de 
dispositivos variados de mensuração de parâmetros corporais é compatível com a busca de objetividade para a avaliação e entendimento das doenças, no mesmo período em que a fisiologia passa de atividade meramente descritiva a método experimental. Números são apresentados como evidências mais confiáveis do que impressões subjetivas, e são mais facilmente transformados em registros "perfeitos".

Ortega prossegue o capítulo apresentando e discutindo as diversas tecnologias de imagem que remodelaram culturalmente os corpos ao longo do século XX. A visão do interior do próprio corpo passa também a representar uma metáfora do conhecimento de si. No seu surgimento, a tecnologia de raios X é percebida como invasiva e imoral, reveladora da intimidade do sujeito, ao mesmo tempo excitante e inaceitável para a moralidade vitoriana da época. Cabe observar que a psicanálise, surgida no mesmo período, é recebida com o mesmo tipo de excitação e restrição. Tecnologias de imagem que se seguem aos raios $\mathrm{X}$, meio século depois, apresentam especificidades, mas têm em comum a sua naturalização - por meio do ocultamento das suas condições de produção - e a conseqüente transformação cultural em produtora inequívoca de verdades sobre os sujeitos, com os mais diversos usos, para além de sua utilidade como ferramenta diagnóstica médica. As visualizações do cérebro propiciadas pelo TC, MRI e PET detêm lugar privilegiado na cultura contemporânea. Instâncias jurídicas e a cultura popular se apropriam e ressignificam as "verdades" produzidas por essas tecnologias. A mídia desempenha papel fundamental nessa rede, propiciando, por sua vez, o surgimento de novas "verdades" que equalizam a imagem com o estatuto cerebral e, adiante, mental e de personalidade.

$\mathrm{O}$ autor chama a atenção para as premissas não explicitadas que modelam essas idéias, que as fazem parecer "naturais". O pressuposto básico delas é que tudo o que se refere ao humano, sem exceção, pode ser compreendido em termos de funcionamento e localização cerebral, sendo apenas uma questão de tempo conseguir-se o controle completo sobre os destinos dos seres humanos. A pessoa é o seu cérebro. As novas imagens oferecem um corpo e uma pessoa sem angústia ou dor, um corpo imaterial e autônomo, embora fragmentado. Prossegue discutindo manifestações de arte contemporânea significativas para a compreensão da cultura somática e de tradição anatômica, como a exposição Bodyworlds, de von Hagens, que traz novas formas de internalidade e intimidade para a concretude de cadáveres plastinados. Constroem-se uma identidade externalizada e novos modos de dar sentido à construção de identidade ou, como pontua Ortega, por meio de uma 
visualidade reencantada, não mais metáfora de interioridade psicológica ou moral. A distinção entre corpo e representação fica esfumaçada, do mesmo modo que ocorre com as novas tecnologias de imagem médica e com o Visible Human Project. Corpos virtuais fazem parte de uma nova anatomia, que servirá para treinar médicos em cirurgias virtuais, em uma medicina cada vez mais digitalizada, em estreita continuidade com as tecnologias de imagem médica. Telecirurgias são analisadas e comparadas com tecnologias de imagem, apresentando-se como as duas faces de uma mesma moeda: o distanciamento progressivo e a intimidade extrema. A espetacularização está intrinsecamente presente, como condição mesma de existência de ambas. O virtual não é mais uma representação do real, ele amplia o real. Uma interioridade visceral torna-se pública, visível e acessível por qualquer um. O corpo e a intimidade perdem a opacidade, com o surgimento de novas modalidades confessionais, sempre mediadas por tecnologias visuais.

Em que pesem essas transformações, Ortega nos mostra a não-existência de ruptura entre digitalização e anatomização, na medida em que o modelo de corpo é o mesmo: atomizado, fragmentado e exposto. Há uma discussão rica sobre a relação entre o real, o virtual e o espetáculo, apresentada como pano de fundo para as tecnologias visuais médicas e seus efeitos sobre a corporeidade. Nessas tecnologias, a imagem produzida torna-se mais real do que o corpo, tornado transparente. $\mathrm{O}$ capítulo se encerra debatendo o papel da visualidade na cultura contemporânea e na construção de verdades "objetivas", a partir da fragmentação do corpo, que tem repercussões nas vivências contemporâneas de corporeidade e nas possibilidades de torná-lo - [re]partido em pedaços - um objeto de consumo. A experiência subjetiva do corpo é eludida. A objetificação do mesmo apresenta também uma série de conseqüências de ordem ética. $\mathrm{O}$ autor nos mostra de que modo a visualização opera nesta fragmentação e objetificação, opondo-se à experiência do corpo unificado, ponto a partir do qual se pensa, sente e age, sujeito da experiência e da ação.

O capítulo final articula os anteriores em torno da discussão do estatuto do corpo. Aborda o debate entre duas posiçōes, a construtivista e a materialista (considerada essencialista por alguns oponentes), que corresponderiam a dois pólos extremos de um espectro amplo de abordagens sobre o corpo. Ortega defende a dimensão encarnada e material da corporeidade, sem se considerar um essencialista, sustentando as vantagens éticas e epistemológicas que essa abordagem representa 
sobre a posição construtivista que, de acordo com ele, recria o mesmo dualismo da tradição que pretende criticar. Desenvolve seu argumento fundamentando sua posição a partir da exposição e discussão de algumas questões levantadas por Foucault, considerado o autor-chave para o construtivismo social.

O construtivismo do corpo surge na obra desse autor nos anos 1970, associado à genealogia do poder. $\mathrm{O}$ ponto crucial do argumento de Foucault é a apresentação dos corpos como produtos sócio-históricos, profundamente maleáveis. Em Vigiar e punir, o corpo é um produto, objeto das tecnologias de poder, infinitamente flexível, "corpos dóceis", analisáveis e controláveis - mas, sobretudo, naturalizados. Ortega se contrapõe à idéia de construção social do corpo, discutindo-a e problematizando-a. Para ele, a idéia de que a experiência subjetiva de materialidade do corpo seja um constructo é questionável, mesmo não se alinhando entre os autores essencialistas. Discute extensivamente a posição construtivista apresentando argumentos que fundamentam sua restrição ao construtivismo radical, que nega a materialidade do corpo considerando-a um efeito do poder. A crítica principal de Ortega a Foucault é que este não se interessaria pela materialidade do corpo como uma entidade ativa e intencional, entendendo o indivíduo como efeito das relações de poder, que se exerceriam fisicamente sobre os corpos. A ênfase dada por Foucault aos controles exercidos sobre os corpos não contemplaria a experiência sensorial de se ter um corpo, exceto nos casos do prazer e do desejo. Para ele, o corpo seria sobretudo símbolo, metáfora, local de exercício do poder. Para seus críticos - entre eles o nosso autor - esta perspectiva seria muito limitante para a compreensão da experiência humana. O privilégio da visão e os dispositivos visuais seriam em parte responsáveis por essa visão descarnada do corpo. Neste ponto preciso surge um impasse na argumentação de Ortega, que aqui parece não considerar que o lugar da visão (e das tecnologias visuais) não se constituiu espontaneamente a partir do nada, embora no capítulo anterior tenha exposto e discutido de maneira didática e minuciosa de que modo esses lugares e papéis foram historicamente construídos.

Entre as conseqüências éticas e epistemológicas da posição construtivista radical, Ortega aponta o "pavor da carne”, a rejeição da corporeidade, cuja expressão empírica seriam os modelos de beleza lipofóbicos, sem gordura alguma, e os projetos de inteligência artificial e realidade virtual. Vísceras, odores e fluidos corporais passariam à ordem da abjeção. Para o autor, o horror da carne das teorias construtivistas (e de parte da obra de Foucault) estaria vinculado à perspectiva 
negativa das ciências sociais em relação à biologia. Este é um ponto bastante interessante para reflexão, levantado por Ortega, pois permite-nos vincular a afirmação de status das ciências sociais com a libertação do modelo das ciências naturais para ter o status científico assegurado, em busca de um modelo próprio. O positivismo estaria "em baixa”, e o "horror da carne" representaria o reflexo disto nas teorias sociais e percepções sobre os corpos.

A discussão acerca da relação entre ciências sociais e biologia se inicia com as implicações filosóficas do darwinismo assinaladas por John Dewey em 1910. Se por um lado a teoria da evolução desconstruía a metafísica tradicional, por outro recrudesceram as filosofias absolutistas e a separação entre filosofia e ciência no decorrer do século XX. Em seguida Ortega expõe as polêmicas e acusações mútuas entre as distintas disciplinas, e a posição mediana apresentada por Maturana, Varela e Lewontin, que apontam que o conhecimento biológico é diferente do determinismo biológico e genético. Outros autores na área neurocientífica e biotecnológica colocam em xeque as dicotomias natureza-cultura, natural-artificial etc., quebrando a oposição entre ciências humanas/sociais e a biologia e propondo a existência de uma fluidez e articulação entre elas mais ampla do que ocorria anteriormente.

Contrapondo o construtivismo à indissolubilidade do corpo e do ambiente e à intencionalidade dos sujeitos, Ortega postula o corpo fenomenológico como saída epistemológica para o entendimento do corpo, e mais, considera que levar em conta a dimensão fenomenológica ou material da corporeidade traria ganhos para o pensamento construtivista e o de Foucault. Em relação a este último, permitiria superar o dualismo, encarando a ação dos sujeitos não apenas como manifestações do poder, e explicando como se exercem na prática as relações de poder. Ortega opõe-se firmemente à perspectiva construtivista na qual a tensão entre ação e estrutura privilegia esta última, a ação dos sujeitos sendo entendida como conseqüência ou manifestação no corpo das relações estruturais de poder. Propõe o corpo fenomenológico como outro modo de compreender a ação: o corpo é o ponto de onde se parte, que fala, conhece e age. $\mathrm{O}$ foco na diversidade de formas como isso ocorre impediria de essencializar a experiência vivida. A ênfase nos aspectos relacionais teria o mesmo sentido, evitando o subjetivismo e o racionalismo e superando a dicotomia sujeito-objeto. Conforma assinala: "Apesar de existirem invariantes estruturais e antropológicos da corporeidade humana, a não-separação do corpo e do ambiente afirma a importância do meio social, cultural e histórico 
na experiência humana" (p. 210). Menciona uma "antropologia mínima" que se basearia em alguns comportamentos invariantes, como por exemplo, a posição ereta ao caminhar. ${ }^{3} \mathrm{Na}$ verdade, uma antropologia sustentada em comportamentos invariantes vem sendo problematizada, no que diz respeito ao corpo, desde o texto clássico de Marcel Mauss, de 1934, sobre as técnicas corporais. Será que, em vez de uma antropologia, não é de um "essencialismo mínimo" que se trata aqui?

Finalmente, Ortega se dedica a dissecar a importância ética e sociopolítica de sua defesa do corpo fenomenológico e da crítica aos construtivismos radicais. Argumenta que tanto o pathos de fragmentação corporal de teóricos pós-modernos quanto os construtivismos radicais se apresentam como ideais ético-emancipatórios contra universalizações totalizantes. Para Ortega, não apenas isto não ocorre, como essas formulações teriam afinidades com o discurso das biotecnologias, que defendem a total maleabilidade do corpo e, portanto, o corpo fenomenológico poderia servir como contraponto crítico a este discurso.

Corpo e tecnologia encontram-se cada vez mais entrelaçados. Próteses de todo tipo, assim como cirurgias, constroem a idéia de que os limites do corpo podem ser drasticamente expandidos e transformados em objetos de consumo - simbólica ou materialmente - com a comercialização de órgãos, por exemplo. Para Ortega, a reafirmação do corpo fenomenológico, com vivência de sua própria corporalidade, funciona como resistência a essa fragmentação, em suas formas variadas, assim como à virtualização na tecnobiomedicina contemporânea.

$\mathrm{O}$ autor sustenta que a tecnobiomedicina, a realidade virtual e a inteligência artificial perpetuam uma perspectiva dualista, agora modificada, entre corpo material e um "eu" imaterial e mental que viaja no espaço cibernético, a materialidade apresentada como uma prisão, limitante, contraposta a infinitas possibilidades do "eu" incorpóreo tecnológico. Este seria, na visão de alguns teóricos, o cogito puro, a superação total do corpo - no fundo, um prolongamento da longa tradição ocidental de esquecimento e desprezo pelo corpo. Ortega aponta que, ao se reiterar a obsolescência do corpo, negam-se as condições que nos fazem humanos. Esta negação de materialidade, afirmada como uma libertação, se mostra falaciosa, pois além de reproduzir as normas dominantes, pode produzir uma situação em que se perca a noção dos limites e das regras básicas de sociabilidade. Caberia assinalar o paradoxo do quanto a suposta libertação propiciada pelos dispositivos tecnológicos atrela e aprofunda a dependência dos sujeitos à tecnologia. 
Ortega recorre ao argumento de Merleau-Ponty, para quem o esquema corporal é um sistema aberto para o mundo. Assim, o ciberespaço, as próteses, cirurgias, transformam o corpo mas não o abolem.

A capacidade fenomenológica do corpo de incorporar próteses e instrumentos ao seu esquema corporal faz da carne uma realidade aberta à técnica, como amplificadora de percepçóes e de faculdade senciente; e o envelope corporal torna-se o lugar de negociação e apropriação desses suplementos, que deixam de exercer apenas a função compensatória de substituição de membros amputados para acrescentar e potencializar a percepção e sensorialidade do indivíduo (p. 225).

Nem por isso a ação deixa de ser corporal. Não confundir com a ação virtual descarnada. Nos discursos de maleabilidade, acessibilidade e virtualidade do corpo fragmentado do construtivismo, desapareceria a idéia da resistência do ambiente à ação corporal do sujeito. Ortega recorre a Winnicott para trabalhar esse ponto, por meio da teoria da ação criativa. A oposição do ambiente à ação corporal provoca o desenvolvimento do impulso criativo e sua experiência. Este só traz prazer no confronto com o ambiente. O ambiente "suficientemente bom" - nos termos de Winnicott - é aquele que proporciona a quantidade adequada de resistência, que permite o desenvolvimento. Demais ou de menos produz doença, perda do sentimento de realidade e do sentimento de que vale a pena viver a vida. Nesse sentido, o espaço virtual onde tudo é possível passa a representar o grande risco de dissolução do tecido social.

Mesmo que, em muitos momentos deste capítulo final, o tom da discussão seja pessimista e um tanto catastrófico, o livro de Francisco Ortega nos mostra claramente que a reflexão pode representar também um modo de resistência e, assim, esse novo corpo - juntamente com a nova anatomia propiciada pelas tecnologias visuais e, especialmente, pelo espaço virtual - não é destino. Pensar criticamente é, sim, o que nos permite construir o futuro e, como parte desse processo, a leitura de $O$ corpo incerto representa um excelente exercício.

\section{Referências}

DASTON, Lorraine; GALISON, Peter. The Image of Objectivity. Representations, v. 0, n.17, Special Issue: Seeing Science, Autumn 1992. p. 81-128. Disponível em http://www.jstor.org/ journals/ ucal.html. Acesso em: 03 jul. 2003. 
MAUSS, Marcel. Les techniques du corps. In: Sociologie et anthropologie. Disponível em:

http://www.uqac.uquebec.ca/zone30/Classiques_de_sciences_sociales/index.html. Acesso em: 26 jun. 2008.

SAWDAY, Jonathan. The Body Emblazoned. Dissection and the Human Body in Renaissance Culture. London: Routledge, 1996.

\section{Notas}

${ }^{1}$ Os programas de computação gráfica de identificação de padrões visuais ainda são muito incipientes. À medida que sejam incrementados e complexificados, esta discussão terá outros contornos.

${ }^{2}$ Cabe observar que as tecnologias de imagem médica, tomando os raios $\mathrm{X}$ como momento inaugural, são posteriores ao surgimento do clorofórmio e da assepsia que, a partir de meados do século XIX, permitiram aos cirurgiōes a visão do interior do corpo vivo, o que teve inegáveis repercussões nas noções construídas sobre o interior do corpo.

${ }^{3}$ Os "meninos-lobo" evidenciam que mesmo o caminhar ereto resulta de um aprendizado sociocultural. Mauss discute em particular, em seu estudo sobre as técnicas corporais - considerado inaugural para a Antropologia do corpo -, as diferenças na marcha entre as distintas culturas (MAUSS, 1934, p. 7-8, 17). 